\title{
Association between hereditary hemochromatosis and hepatocellular carcinoma: a comprehensive review
}

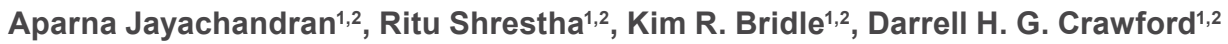 \\ 'The University of Queensland, Faculty of Medicine, Brisbane, QLD 4006, Australia. \\ ${ }^{2}$ Gallipoli Medical Research Institute, Greenslopes Private Hospital, Brisbane, QLD 4120, Australia.
}

\begin{abstract}
Correspondence to: Prof. Darrell H. G. Crawford, Gallipoli Medical Research Institute, The University of Queensland, Faculty of Medicine, Lower Lobby Level, Administration Building, Greenslopes Private Hospital, Greenslopes, QLD 4120, Australia.

E-mail: d.crawford@uq.edu.au
\end{abstract}

How to cite this article: Jayachandran A, Shrestha R, Bridle KR, Crawford DHG. Association between hereditary hemochromatosis and HCC: a comprehensive review. Hepatoma Res 2020;6:8. http://dx.doi.org/10.20517/2394-5079.2019.35

Received: 15 Nov 2019 First Decision: 10 Dec 2019 Revised: 4 Feb 2020 Accepted: 18 Feb 2020 Published: 6 Mar 2020

Science Editor: Guang-Wen Cao Copy Editor: Jing-Wen Zhang Production Editor: Tian Zhang

\begin{abstract}
Hepatocellular carcinoma (HCC) is a significant global health problem with high morbidity and mortality. Its incidence is increasing exponentially worldwide with a close overlap between annual incidence and death rates. Even though significant advances have been made in HCC treatment, fewer than $20 \%$ of patients with $\mathrm{HCC}$ are suitable for potentially curative treatment. Hereditary hemochromatosis $(\mathrm{HH})$ is an important genetic risk factor for HCC. HH is an autosomal recessive disorder of iron metabolism, characterised by elevated iron deposition in most organs including the liver, leading to progressive organ dysfunction. HCC is a complication of $\mathrm{HH}$, nearly always occurring in patients with cirrhosis and contributes to increased mortality rates. Identifying the susceptibility of development of HCC in $\mathrm{HH}$ patients has gained much traction. This review summarises the current knowledge with regard to the association of $\mathrm{HH}$ and $\mathrm{HCC}$ in order to encourage further research. In this review, we focus particularly on HFE gene-related $\mathrm{HH}$. Herein, we highlight and discuss emerging clinical research which addresses the prevalence of $\mathrm{HCC}$ in $\mathrm{HH}$ patients and the coincidence of $\mathrm{HH}$ with other risk factors for $\mathrm{HCC}$ development. We also focus on the therapeutic tools in the management of $\mathrm{HCC}$ associated with $\mathrm{HH}$.
\end{abstract}

Keywords: Hepatocellular carcinoma, hereditary hemochromatosis, HFE gene, C282Y mutation, H63D mutation, liver cirrhosis 


\section{INTRODUCTION}

Hepatocellular carcinoma (HCC) is considered to be the most frequent primary liver cancer accounting for $80 \%-90 \%$ of cases $^{[1]}$. HCC has become a leading cause of cancer-related death globally in the last decades, accounting for approximately 800,000 deaths annually ${ }^{[2]}$. The incidence of HCC continues to escalate by $3 \%-9 \%$ cases annually worldwide with a nearly equal proportion of deaths ${ }^{[3]}$. Surgical resection, transarterial chemoembolization radiofrequency ablation and liver transplantation remain the treatments of choice for HCC patients and are beneficial for patients in the early stages of the disease ${ }^{[4]}$. The prognosis for HCC patients in the advanced stages is poor due to the limited efficacy of current therapy ${ }^{[5]}$.

Implementing HCC surveillance among at-risk populations is imperative to identify HCC at early stages amenable to curative treatments. HCC mostly develops in patients with underlying chronic hepatic disease $^{[6-8]}$. Several at-risk populations for HCC have been identified including patients with cirrhosis, hepatitis B and hepatitis C viral infection, alcoholism, aflatoxin, non-alcoholic steatohepatitis, type 2 diabetes, obesity and Wilson's Disease ${ }^{[7]}$. Hemochromatosis is also an important risk factor for HCC.

Hereditary hemochromatosis $(\mathrm{HH})$ is a common inherited iron metabolism disorder, characterised by increased deposition of iron in the liver and other organs. If left untreated, hepatic iron overload in $\mathrm{HH}$ patients can result in liver injury, which can progress to cirrhosis and subsequently $\mathrm{HCC}^{[9,10]}$. Further clarification of the risk factors in individual HH patients for HCC development remains an area of unmet clinical need. Herein, we review the current literature concerning the association between HH and HCC with a focus on $H F E$ gene-related $\mathrm{HH}$. This review highlights and discusses clinical studies that address the prevalence of HCC in HH and risk factors linked with the development of HCC in patients with HH.

\section{HEREDITARY HEMOCHROMATOSIS}

HH comprises a number of inherited diseases of iron metabolism ${ }^{[1]}$. Although its geographic distribution is worldwide, $\mathrm{HH}$ is one of the most common genetic disorders in individuals of Northern European ancestry, particularly Nordic or Celtic ancestry. In this population, the frequency of homozygous HFE mutation is approximately 1 in 200-250 individuals, ${ }^{[9,12-14]}$. There is considerable phenotypic diversity in $\mathrm{HH}$ and associated biochemical changes are more common than the clinical manifestations of iron overloadrelated disease. Indeed, advanced clinical expression of HFE-related hemochromatosis is rare ${ }^{[15]}$. This autosomal recessive condition is characterised by excessive iron absorption by the small intestine. This leads to progressive iron loading over many years of the affected individual's adult life. As hepatocytes store most of the excess iron, the liver is the organ mostly afflicted by iron overload ${ }^{[16,17]}$. Long-term effects of excessive iron loading include liver fibrosis, cirrhosis, HCC, cardiomyopathy, diabetes mellitus, hypogonadism and arthropathy ${ }^{[10,11]}$. Early studies suggested that liver disease was the most frequent cause of death in HH individuals ${ }^{[18]}$. However, more readily available genetic testing, greater public awareness and an improved understanding of the natural history of the condition means that most affected subjects are now diagnosed before significant target organ injury occurs.

$\mathrm{HH}$ is classified into 6 groups depending on the nature of the underlying genetic mutation ${ }^{[17]}$. Mutations in the high iron gene (HFE) (Hemochromatosis Type 1, i.e., C282Y homozygosity, C282Y/H63D compound heterozygosity and other HFE-related genotypes, e.g., $\mathrm{S} 65 \mathrm{C}$ ) are responsible for the majority of hemochromatosis cases ${ }^{[19]}$. Rarer forms of non-HFE associated HH have been attributed to mutations in hemojuvelin (HJV) (Hemochromatosis Type 2a), hepcidin (HAMP) (Hemochromatosis Type 2b), transferrin receptor 2 (TFR2) (Hemochromatosis Type 3), ferroportin (SLC40A1) (Hemochromatosis Type 4) and ferritin heavy chain $1(F T H 1)$ (Hemochromatosis Type 5) gene ${ }^{[1]]}$. These latter conditions are thought to account for most of the non-HFE forms of $\mathrm{HH}^{[9]}$. 


\section{Hemochromatosis type 1}

HFE is located on chromosome 6p21.3, has seven exons and five introns and encodes for a 343-amino acid protein that is similar to human leucocytes antigen class I molecules ${ }^{[20]}$. The HFE gene is important for normal iron metabolism. Feder et al. ${ }^{[19]}$ first identified that a mutation in this gene caused $\mathrm{HH}$. The three most common mutations at exons $2(187 \mathrm{C} \rightarrow \mathrm{G}$ and $193 \mathrm{~A} \rightarrow \mathrm{T})$ and exon $4(845 \mathrm{G} \rightarrow \mathrm{A})$ of the HFE gene were linked with $\mathrm{HH}^{[19]}$. However, not all $\mathrm{HH}$ patients harbour these mutations, as outlined above ${ }^{[21]}$.

\section{C282Y $(845 G \rightarrow A)$ homozygotes}

About $80 \%-85 \%$ of individuals with $\mathrm{HH}$ are $\mathrm{C} 282 \mathrm{Y}(845 \mathrm{G} \rightarrow \mathrm{A})$ homozygotes. This founder mutation leads to a single-base change, resulting in the substitution of tyrosine (Y) for cysteine (C) in the amino acid sequence of the HFE protein at position $282^{[10]}$. HFE-related $\mathrm{HH}$ is an adult onset disorder and in expressing patients is characterised by increased transferrin saturation and serum ferritin levels compared to the healthy population ${ }^{[22]}$. Moreover, $C 282 Y$ homozygotes are at particular risk of cirrhosis if serum ferritin levels are greater than $1000 \mu \mathrm{g} / \mathrm{L}^{[23]}$. Males and $C 282 \mathrm{Y}$ homozygotes of family members affected by $\mathrm{HH}$ exhibit a higher penetrance of homozygous $C 282 Y$ gene ${ }^{[22]}$. However, due to the variable phenotypic expression of this mutation, only some of these patients develop cirrhosis or $\mathrm{HCC}^{[22]}$. The frequency of the $C 282 Y$ allele is high in European populations and the reported frequency varies from $0 \%-3 \%$ in South Europe to $4 \%-10 \%$ in North Europe ${ }^{[20,24]}$.

This HFE mutant protein has reduced cell surface expression and undergoes rapid degradation. The mechanisms by which HFE protein regulates iron homeostasis at the cellular level are beginning to emerge. Earlier studies proposed that the HFE protein binds the transferrin receptor 1 (TFR1) to form a stable complex, which in turn decreases its binding affinity for transferrin. The HFE mutant protein does not form this complex, which results in transferrin binding to the transferrin receptor, leading to increased cellular uptake of iron and subsequently causing iron overload ${ }^{[25,26]}$. Recent studies have demonstrated that the HFE protein is an upstream regulator of the hormone hepcidin in hepatocytes ${ }^{[27,28]}$. Hepcidin is synthesised and secreted by hepatocytes and is a master regulator of iron homeostasis in the body. Hepcidin negatively regulates dietary iron uptake by the intestine ${ }^{[29]}$. Under physiological conditions, hepatic hepcidin expression is regulated by proteins that are predominantly expressed in hepatocytes, including HFE, transferrin receptor 2 (TFR2), HJV, bone morphogenetic protein 6 (BMP6), matriptase-2 and transferrin ${ }^{[29,30]}$. HH patients harbouring the HFE mutations have low levels of hepcidin protein allowing a slow accumulation of iron over the individual's lifetime, resulting in iron overload ${ }^{[31]}$. Iron overload induces reactive oxygen species (ROS) formation, which causes DNA damage and somatic mutations that may play a role in the subsequent development of HCC over time ${ }^{[32]}$.

\section{HFE compound heterozygotes}

Two other mutations in the HFE gene, namely $187 \mathrm{C} \rightarrow \mathrm{G}(H 63 \mathrm{D})$ and $193 \mathrm{~A} \rightarrow \mathrm{T}(S 65 \mathrm{C})$, have been identified $^{[33,34]}$. These additional mutations alone have not been implicated in iron overload. However, the co-occurrence of these mutations together with a $C 282 Y$ mutation forming a compound heterozygote $\left(C 282\right.$ Y/H63D or $C 282$ Y/S65C) has been implicated in iron overload ${ }^{[35]}$. HFE compound heterozygotes might have increased iron indices but iron overload-related disease is most uncommon ${ }^{[36,37]}$. Clinical disease may develop in HFE compound heterozygotes in conjunction with comorbid factors such as obesity, excess alcohol consumption or diabetes ${ }^{[37]}$. The Netherlands and the Iberian Peninsula have a high frequency of the $H_{63} \mathrm{D}$ allele that varies from $7.9 \%$ to $17.5 \%$ in the general population ${ }^{[38]}$. The frequency of S65C allele is low, 0\%-1\% in European and Brazilian populations ${ }^{[12,34,39]}$. Approximately $5 \%$ of individuals with a clinical diagnosis of $\mathrm{HH}$ are compound heterozygotes ${ }^{[40,41]}$.

\section{THE ASSOCIATION BETWEEN HH AND HCC}

HCC develops in $\mathrm{HH}$ individuals and contributes to the increased mortality ${ }^{[42-47]}$. Although the biological and physiological functions of HFE gene within the liver are not fully understood, several case-control 
and population-based studies have confirmed that HFE mutations confer increased risk for HCC development ${ }^{[48-57]}$. The exact incidence and prevalence of HCC varies considerably between different studies, which is probably explained by the heterogeneity of the study cohorts. The characteristics of the study cohort is critical in the interpretation of such studies given the variable phenotype of $\mathrm{HH}$ and also because cirrhosis is such a critical risk factor for the development of HCC. Some studies report on cohorts where a large proportion of patients had underlying cirrhosis. Other studies have clear referral bias due to the authors' interest in disorders of iron metabolism, are retrospective in nature or are from liver transplant programs where one would expect cirrhosis and HCC to dominate the study cohort.

Population-based studies provide a more realistic assessment of the overall incidence and prevalence of HCC in HH. In one such study, the US National Centre for Health Statistics reported a close association between HH and HCC. In this study, patients who were diagnosed with $\mathrm{HH}$ and who died were 23 -fold more likely to have HCC in comparison with individuals without a diagnosis of $\mathrm{HH}^{[47]}$. A further study conducted in Sweden reported the risk of HCC in HH individuals to be approximately 20 -fold higher than in the general population ${ }^{[42]}$. At 10 years of follow up, the absolute risk of HCC among HH men was $6 \%$, which was higher than the risk in women $(1.5 \%)^{[42]}$. Willis et al. ${ }^{[58]}$ found that HCC patients had a 7\% prevalence of the $C 282 Y$ homozygous mutation. In a similar study, Sánchez-Luna et al. ${ }^{[59]}$ found that, among 118 C282Y homozygotes, eight homozygotes developed HCC, representing $1.8 \%$ of patients with HCC.

Meta-analyses have recently been conducted to clarify the effect of HFE polymorphisms on the susceptibility to HCC. Ellervik et al. ${ }^{[60]}$ conducted a meta-analysis to examine associations between C282Y and H63D mutations with HCC. An odds ratio of 11 for HCC occurrence was reported for C282Y homozygotes (YY vs. CC). A further study conducted on 43 published articles ( 5758 cases and 14,741 controls) demonstrated that the HFE C282Y homozygous mutation was significantly associated with increased risk of HCC compared to the overall population ${ }^{[61]}$. Another meta-analysis including nine studies based on European populations (1102 HCC cases and 3766 controls) showed an association between the Y allele of $\mathrm{C} 282 \mathrm{Y}$ and HCC risk overall as well as in alcohol-related cirrhosis patients but not in viral-related cirrhosis patients $^{[51]}$. There are also contrary reports showing no association with the risk of developing HCC $^{[23,33,55,62,63]}$, possibly reflecting the low penetrance of the $C 282 Y$ mutation in the populations studied.

\section{Cirrhosis and other risk factors for HCC development in $\mathrm{HH}$}

HCC accounts for $25 \%-45 \%$ of disease-related premature deaths in $\mathrm{HH}^{[64]}$. In $\mathrm{HH}$, the primary risk factor for the development of HCC is the presence of cirrhosis. Studies that have assessed the association of risk factors for development of HCC in HH are listed in Tables 1 and 2. Some studies have indicated that the risk of HCC in cirrhotic $\mathrm{HH}$ patients is higher than in patients with cirrhosis from other causes. In a metaanalysis assessment of eight studies which included follow up of cirrhotic patients, the annual incidence of HCC was $1.20 \%$ per year ${ }^{[65]}$. One other study showed that, once cirrhosis has been established in HH patients, the annual incidence of HCC is approximately $4 \%{ }^{[66]}$. Earlier studies have revealed that risk of HCC developing in cirrhotic HH patients was 200 -fold higher than non-cirrhotic control groups ${ }^{[18,67]}$. These studies may have suffered referral bias and lacked HFE genetic testing with the diagnosis of $\mathrm{HH}$ based on clinical features and biochemical test ${ }^{[18,67]}$. Recent studies utilised a combination of HFE genotyping, clinical examination and abnormal iron indices including transferrin saturation, serum ferritin, and iron deposition in liver biopsies to confirm diagnosis of $\mathrm{HH}^{[42,44]}$. These studies have revealed that risk of HCC developing in cirrhotic HH patients was 20 -fold higher than non-cirrhotic control groups ${ }^{[42,44,48]}$. It is worth noting that HCC has occasionally been found to occur in HH patients with no cirrhosis ${ }^{[64,68,69]}$. In these patients, hepatic iron accumulation has been suggested to be directly involved in HCC development independently of cirrhosis ${ }^{[64,69,70]}$. An increased risk of HCC with cirrhosis among individuals heterozygous for HFE gene mutations has also been reported and is discussed below ${ }^{[42,51]}$. 


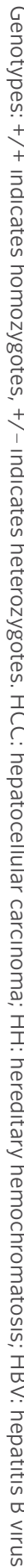

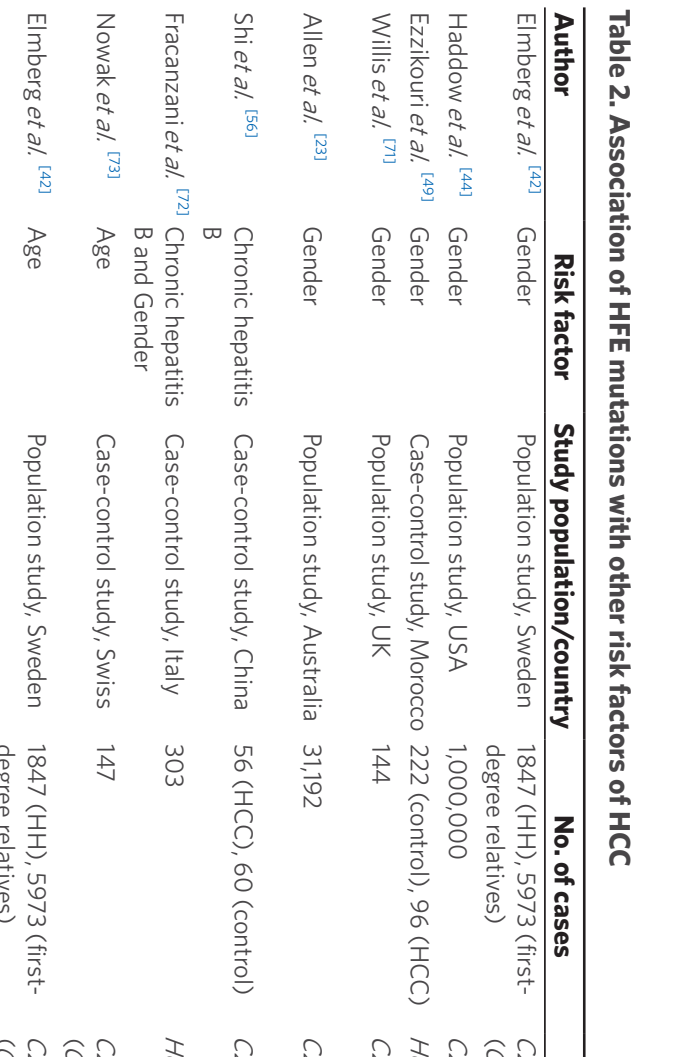

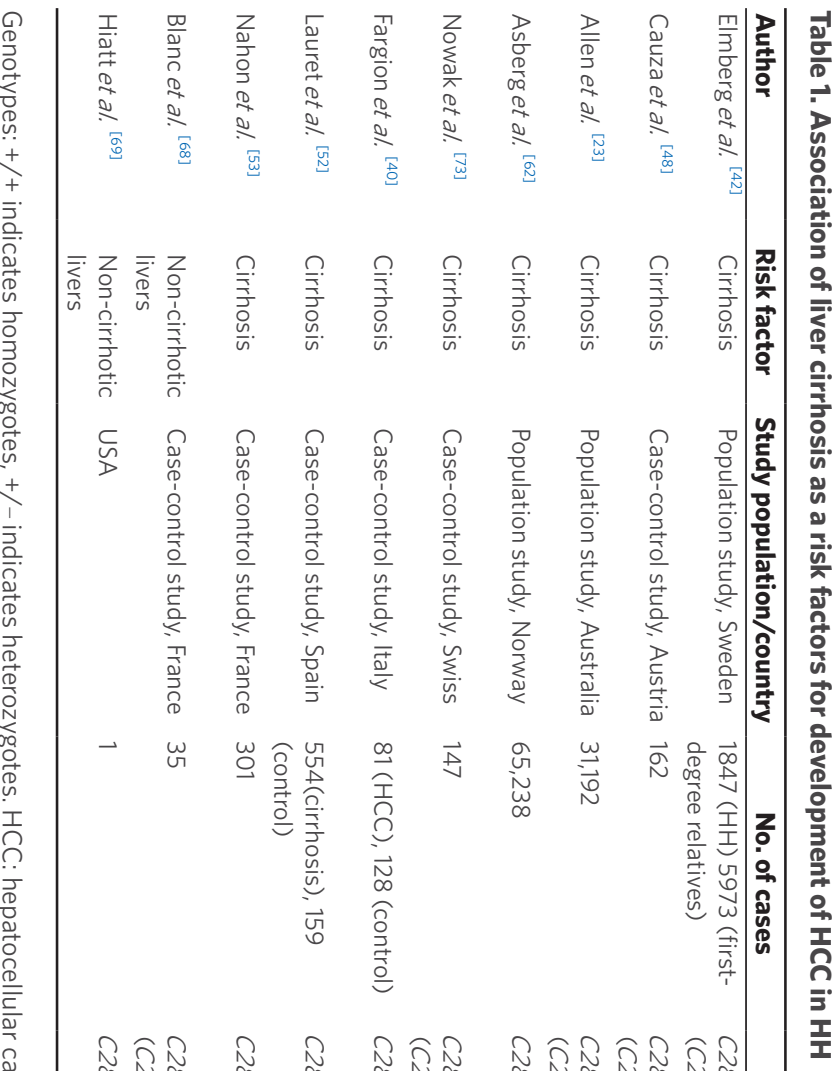

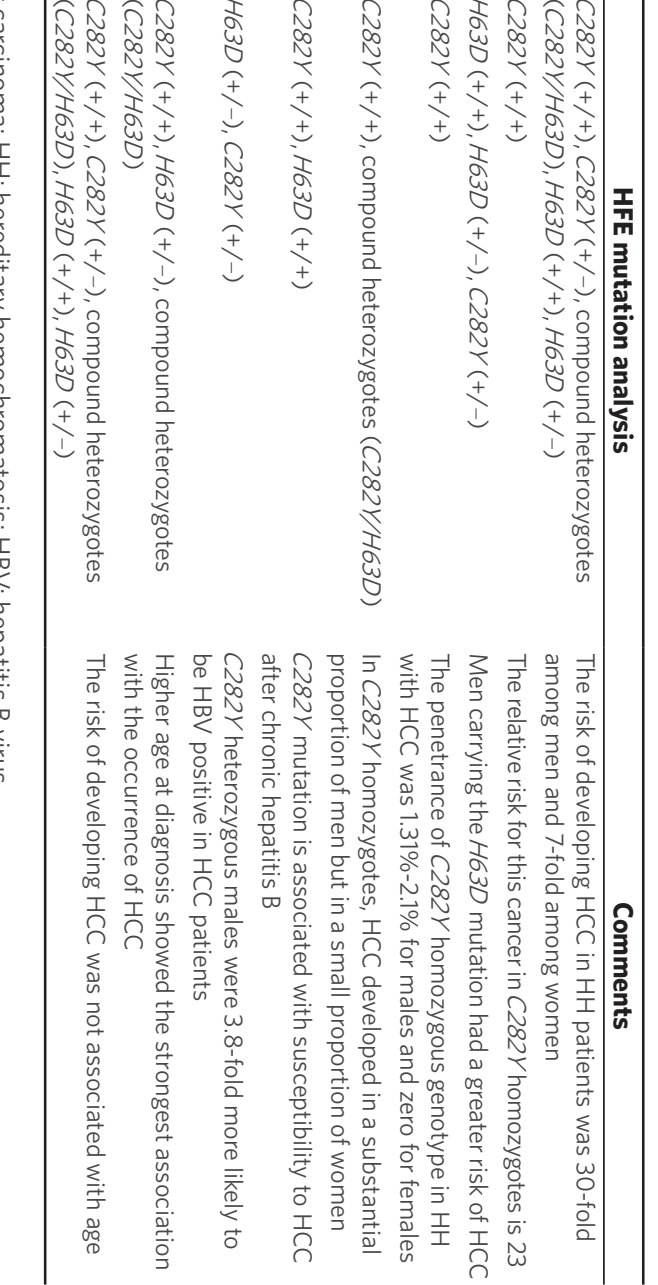

言

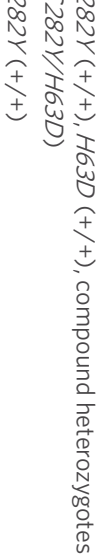
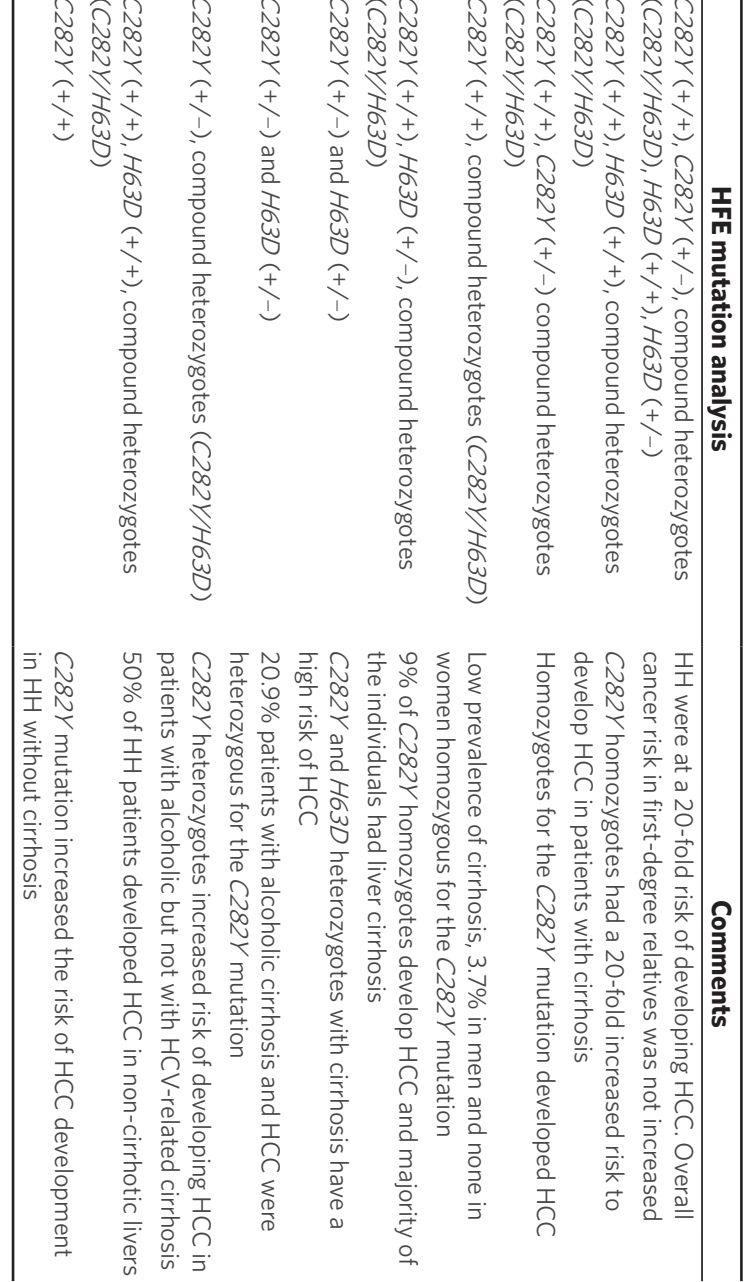
Other risk factors that may synergise with cirrhosis include chronic viral hepatitis, alcohol abuse, diabetes, age and gender ${ }^{[47,71]}$ [Table 2]. Patients with HCC and diabetes mellitus were 82 times more likely to have $\mathrm{HH}^{[47]}$. The risk of HCC was higher in males who were $C 282 Y$ homozygotes when compared to C282Y homozygous females - reflecting in part the higher iron burden in men ${ }^{[4,49,71]}$. A study reported $1.3 \%-2.1 \%$ penetrance of the $C 282 Y$ homozygous genotype in HH patients with HCC for males and zero for females ${ }^{[71]}$. Another study found penetrance of the $\mathrm{C} 282 \mathrm{Y}$ homozygous genotype in male $\mathrm{HH}$ patients with $\mathrm{HCC}$ was $5.56 \%{ }^{[23]}$. Studies have also found an unequivocal relationship between risk of HCC and C282Y mutation in patients with chronic hepatitis B and male gender ${ }^{[56,72]}$. Another study identified increased age at diagnosis as a strong predictor for the development of HCC in HH patients and the authors suggested that this is a surrogate marker of duration of exposure to iron ${ }^{[73]}$. This latter finding has not been substantiated in other studies. Serum ferritin level of above $1000 \mathrm{mg} / \mathrm{L}$ at diagnosis confirming high iron overload was a risk factor for HCC in the study by Nowak et al. ${ }^{[73]}$. A serum ferritin concentration of over $1000 \mathrm{mg} / \mathrm{L}$ is also associated with a high risk of cirrhosis, which is the likely explanation for that association. In contrast to other studies, this study found no association between alcohol consumption and HCC development ${ }^{[73]}$. However, the level of alcohol consumption defined as "considerable" was greater than $10 \mathrm{~g} /$ day for women and $20 \mathrm{~g} /$ day for men and this may below the oncogenic threshold.

Collectively, these data illustrate that the presence of cirrhosis is the primary risk factor for the development of HCC in patients with $\mathrm{HH}$. Other risk factors, as discussed above, seem to amplify the oncogenic potential of cirrhosis. Importantly, some of these other risks can be reduced by lifestyle modifications and/ or therapy of other liver diseases, particularly chronic viral hepatitis.

\section{HFE heterozygotes and the risk of HCC in patients with cirrhosis of other causes}

This area is controversial and there are conflicting data on the role of heterozygosity for HFE mutations in the development of HCC in patients with cirrhosis from other causes. For example, Hellerbrand et al. ${ }^{[51]}$ indicated that HCC patients with cirrhosis were more likely to be $C 282 Y$ heterozygotes compared to cirrhotic patients without HCC or normal controls. Additionally, elevated levels of transferrin saturation, serum ferritin and liver iron deposition were reported in HCC patients harbouring the heterozygous C282Y mutation compared to those lacking this mutation, suggesting that altered hepatic iron metabolism played a pathogenic role ${ }^{[51]}$. The prevalence of the heterozygous $C 282 Y$ and $H 63 D$ mutation was also observed to be higher in 81 Italian patients with cirrhosis and HCC than in 128 normal controls $(8.6 \% \text { vs. } 1.6 \%)^{[50]}$. Similarly, Lauret et al..$^{[52]}$ found a $20.9 \%$ prevalence of the C282Y heterozygous mutation in 43 Spanish HCC patients. In 301 cirrhotic French patients prospectively followed up for six months, hepatic iron overload and the heterozygous $C 282 Y$ mutation were associated with an increase in the incidence of HCC in cirrhotic patients with alcohol-related problems but not in patients with hepatitis $\mathrm{C}$ viral infection ${ }^{[53]}$.

In contrast, a large prospective multicentre French study compared the prevalence of HFE mutations in 133 cirrhotic patients with HCC and 100 cirrhotic patients without HCC with a follow up of 2.5 years ${ }^{[7]}$. This study concluded that $\mathrm{C} 282 Y$ mutation is not linked to an increased risk of HCC in cirrhotic patients ${ }^{[74]}$. Similarly, in another study of 162 patients with HCC and cirrhosis, the frequency of the C282Y mutation did not differ between the patients with cirrhosis or healthy controls ${ }^{[4]}$.

Initially, it was proposed that the $H 63 D$ mutation has no direct association with $\mathrm{HH}^{[19,33]}$. In line with this, several studies reported no association between the prevalence of the $H 63 D$ mutation and the risk of developing $\mathrm{HCC}^{[75]}$. Conversely, other studies have implicated occurrence of H63D mutation with an increased risk of HCC in HH patients ${ }^{[5,61,63]}$. In a study of 196 HCC patients and 181 healthy controls, the $H 63 D$ mutation was associated with an increased risk of $\mathrm{HCC}^{[55]}$. HCC developed in HH patients exhibiting $H 63 D$ mutations along with predisposing factors such as liver cirrhosis due to chronic hepatitis $\mathrm{C}$ virus infection and/or ethanol abuse and chronic hepatitis B virus-infection ${ }^{[55]}$. Another large study 
involving 5758 cases and 14,741 controls demonstrated that $H 63 D$ mutation was more likely to be involved in susceptibility to HCC without cirrhosis in the African population ${ }^{[6]]}$. A positive association between compound heterozygosity for $\mathrm{C}_{2} 82 \mathrm{Y} / \mathrm{H} 63 \mathrm{D}$ and the risk of HCC was also observed ${ }^{[61]}$. Conversely, no cases of HCC were identified among the 44 compound heterozygotes examined in another study ${ }^{[59]}$. In an Egyptian cohort study, patients with the $H_{63} D$ mutation had a higher risk of developing $\mathrm{HCC}^{[63]}$. Additionally, the role of $565 C$ in HCC remains to be elucidated. A number of other studies demonstrated that individuals harbouring $\mathrm{C} 282 \mathrm{Y}$ or $\mathrm{H6} 3 \mathrm{D}$ mutation did not develop HCC, suggesting there was no association between HFE mutation and $\mathrm{HCC}^{[74,76-78]}$. Thus, whether there is a link between these HFE mutations and the HCC risk remains somewhat uncertain with significant variation between different populations groups, and different underlying diseases. More studies are needed to definitively assess the influence of the HFE mutations on the development of HCC in HH patients.

\section{Mechanisms of iron toxicity in HH leading to HCC}

Iron is ubiquitously present in cells and a physiological optimal balance of iron is critical for the normal functioning of cells ${ }^{[79,80]}$. Iron is essential for several important processes including the transfer of oxygen throughout the body by haemoglobin, the mitochondrial electron transport chain and as a cofactor in enzymatic reactions. However, excess iron can be very toxic to the cell due to its redox reactivity that promotes oxidative stress ${ }^{[81,82]}$. Homeostasis of iron in the body is maintained by four major cell types: duodenal enterocytes (dietary iron absorption), erythroid precursors (iron utilisation), reticuloendothelial macrophages (iron storage and recycling) and hepatocytes (iron storage and endocrine regulation) ${ }^{[83]}$. Duodenal enterocytes absorb dietary iron and store it in the form of ferritin. Enterocytes release iron into the circulation through the basolateral iron exporter, ferroportin. In the blood stream, iron binds to the plasma iron transport protein transferrin ${ }^{[82,84]}$. The majority of iron in the body is found in the oxygencarrying haemoglobin of erythrocytes. Iron is also stored in the form of ferritin in hepatocytes and reticuloendothelial macrophages. The macrophages phagocytose the senescent erythrocytes and the iron from haemoglobin is loaded onto transferrin for iron recycling ${ }^{[83]}$. Importantly, in humans, there are no active mechanisms to eliminate excess iron from the body ${ }^{[15,42]}$.

Transferrin is highly saturated during iron overload and additional iron released into the circulation binds to low-molecular-weight compounds and is termed non-transferrin bound iron (NTBI). Excess iron in circulation enters into hepatocytes by binding the transmembrane TFR1 and TFR2 on hepatocytes ${ }^{[17,83]}$. While both TFR1 and TFR2 are capable of iron uptake, TFR1 has a higher iron binding affinity than TFR2. TFR2 is an iron sensor that regulates body iron uptake and is sensitive to changes in transferrin saturation in the blood ${ }^{[82,85]}$. Hepatocytes have a significant role in iron homeostasis as they also produce the hormone hepcidin, an important regulator of iron balance ${ }^{[86]}$. Hepcidin binds ferroportin and stimulates the internalisation and subsequent degradation of ferroportin, thus decreasing the absorption of iron from the gut and release of iron into the circulation ${ }^{[84]}$. HFE works in conjunction with multiple proteins including TFR2 and Hemojuvelin to induce hepcidin expression ${ }^{[87]}$. In HH patients harbouring the HFE mutations, the hepcidin protein is not properly expressed, which leads to uncontrolled iron absorption, resulting in iron overload ${ }^{[17]}$. In addition, HFE mutation also leads to a loss of transferrin sensitivity, suggesting that TFR2 and HFE complex may be involved in iron-sensing ${ }^{[88]}$. The hepcidin-mediated increased iron absorption from the gut leads to preferential iron loading of the hepatocytes. It has been hypothesised that this in turn causes injury and subsequent malignant transformation of hepatocytes ${ }^{[79,89]}$. The mechanisms responsible for a direct hepatocarcinogenic effect of iron have yet to be fully elucidated ${ }^{[79,89]}$.

Increase in iron absorption over time leads to iron accumulation in hepatocytes, leading to injury and subsequent malignant transformation of hepatocytes ${ }^{[79,89]}$. The role of iron in hepatocarcinogenesis has been suggested from epidemiologic studies, animal models and in vitro studies ${ }^{[00-93]}$. The carcinogenic effect of iron has been related to its ability to form mutagenic hydroxyl radicals, enhance lipid peroxidation, promote immune escape or facilitate chronic inflammation leading to cirrhosis. 
One of the mechanisms by which iron accumulation in the liver may promote malignant transformation of hepatocytes is directly by the mechanism of oxidative stress ${ }^{[79]}$. It has been proposed that the formation of free radicals by Fenton reaction causes oxidative stress, leading to the malignant transformation of hepatocytes ${ }^{[94]}$. Although the Fenton reaction has been implicated in carcinogenic effect of iron, there is relatively little direct or experimental data to support this claim. The excess ferrous iron $\left(\mathrm{Fe}^{2+}\right)$ accumulates in hepatocytes and undergoes a Fenton reaction by interacting with hydrogen peroxide to form $\mathrm{Fe}^{3+}$ and highly reactive oxygen free radicals (ROS $)^{[95]}$. Generation of ROS causes hepatocyte injury by inducing peroxidation of membrane fatty acids followed by the production of toxic by-products that disrupt DNA and protein synthesis ${ }^{[79,94,96]}$. In addition, ROS causes DNA damage and mutagenesis, which may lead to neoplastic transformation over time ${ }^{[97-99]}$. Iron-generated ROS can induce mutations in $p 53$, an important tumour suppressor gene ${ }^{[100]}$. Iron-generated ROS also contributes to the production of a mutagenic and cytotoxic oxidatively DNA-damaged product, 8 -hydroxy-2'-deoxyguanosine $(8-\mathrm{OHdG})^{[101,102]}$. 8 -OHdG causes G:C to T:A transversions, DNA unwinding and strand breaks ${ }^{[101,103,104]}$. A study has shown correlation of 8 -OHdG levels with iron levels in serum in HCC patients ${ }^{[101]}$. In liver tissue, the rate of DNA unwinding and strand breaks have been associated with 8 -OHdG levels ${ }^{[90]}$. Another study has highlighted the link between DNA unwinding and the risk of HCC in HH patients ${ }^{[18]}$. An abnormal form of NTBI, called labile plasma iron or reactive plasma iron, also contributes to oxidative stress and the subsequent liver damage during $\mathrm{HH}^{[105]}$. Overall, several studies support the role of iron-induced ROS formation as the main mechanism of development of HCC in $\mathrm{HH}^{[32,80,99,106,107]}$.

Iron accumulation can also lead to cirrhosis and the subsequent development of HCC, indirectly through the induction of chronic inflammation ${ }^{[79]}$. Excess hepatic iron promotes the activation of hepatic stellate cells in $\mathrm{HH}^{[92]}$. This can promote fibrogenesis. Iron has also been shown to induce transforming growth factor-beta, which plays an important role in the development of liver fibrosis ${ }^{[108]}$. The combination of elevated iron levels with environmental and acquired factors such as excessive alcohol consumption, viral hepatitis and steatosis may act synergistically to precipitate the development of $\mathrm{HCC}^{[109]}$. Iron has a direct effect on tumour growth by promoting cellular proliferation. In human HCC cell lines, iron enhances proliferation and iron deprivation leads to cell cycle arrest and increased apoptosis ${ }^{[110]}$. It has been reported that increased iron concentration in HCC cells was associated with enhanced migration, invasion, high metastasis rate and recurrence ${ }^{[111]}$.

In addition, iron reduces immune surveillance for malignant transformation by impairing T-cell proliferation and inhibiting tumoricidal activity of macrophages ${ }^{[7,103,104,112,13]}$. Epigenetic alterations due to iron overload have also been implicated in hepatocarcinogenesis. Epigenetic defects such as increased DNA methylation commonly occur in $\mathrm{HCC}^{[114]}$. Lehmann et al. ${ }^{[15]}$ found $84 \%$ of the non-cancerous liver biopsies derived from $\mathrm{HH}$ patients exhibited hypermethylation of genes that are often hypermethylated in HCC. DNA hypermethylation was independent of age, cirrhosis or hepatitis infection. Several studies support the role of iron in the development of HCC in HH.

\section{Diagnosis and treatment of HCC in HH patients}

Prior to the identification of HFE, the diagnosis of $\mathrm{HH}$ was based on parameters including clinical features, increased ferritin levels, high serum transferrin saturation and characteristic findings on liver biopsy ${ }^{[17]}$. After the discovery of the HFE mutations, genetic screening became the preferred diagnostic test for HH. $H F E$ genetic testing together with measurements of serum transferrin saturation and ferritin levels have gained traction as the diagnostic test of choice for $\mathrm{HH}^{[9-11]}$. A serum ferritin concentration of $>1000 \mu \mathrm{g} / \mathrm{L}$ in patients with $\mathrm{HH}$ has been associated with an increased risk of cirrhosis and $\mathrm{HCC}^{[11]}$. Magnetic resonance imaging (MRI) has recently been applied as an imaging modality for the detection and quantification of hepatic iron in those patients where there is diagnostic uncertainty. Additionally, MRI can be utilised to evaluate HCC in $\mathrm{HH}$ patients ${ }^{[17]}$. 
Excess iron should be removed by venesection (phlebotomy) therapy and this should eliminate the risk of progression to cirrhosis and the development of HCC in non-cirrhotic individuals. Early diagnosis and iron depletion therapy has the potential of improving the survival rate of patients ${ }^{[9]}$. $\mathrm{HH}$ is readily treated by venesection therapy, which is very efficient in removing excess iron and involves two successive treatment phases ${ }^{[116]}$. In the initial induction phase, the excess iron present at the time of diagnosis is removed by 1-2 weekly venesections (7.5 $\mathrm{mL} / \mathrm{kg}$ body weight per venesection). After the removal of excess iron, maintenance therapy, the second treatment phase, prevents recurrent iron overload. Maintenance therapy involves removal of 2-4 units/year ${ }^{[117]}$.

Although venesection is the treatment of choice in hemochromatosis, other iron depletion therapies have also been tested in $\mathrm{HH}$ patients ${ }^{[118,119]}$. Another iron depletion therapy involves the application of iron chelation therapy to facilitate iron mobilisation and excretion. The iron chelating drugs desferioxamine, deferiprone and deferasirox have been tested in HH patients ${ }^{[118,119]}$. A phase I/II clinical trial for deferasirox has shown it to reduce iron burden in $\mathrm{HH}$ patients homozygous for the C282Y mutation ${ }^{[118]}$. Desferioxamine is administered either by intravenous or subcutaneous route, while deferiprone and deferasirox are oral iron chelators. These iron chelators have several side effects including skin rashes, gastrointestinal disturbances and occasionally abnormal liver function tests and should only be considered in patients in whom venesection is not a possibility ${ }^{[118]}$. Of interest, iron chelators with antitumor properties and favourable toxicity profiles have emerged ${ }^{[120]}$. Several iron chelators with effective antitumor activities have been identified [Triapine (3-aminopyridine-2-carboxaldehyde thiosemicarbazone), DpT (di-2pyridylketone thiosemicarbazone) and PKIH (di-2-pyridylketone isonicotinoyl hydrazone) analogues] but these are not routinely used in clinical practice ${ }^{[120-122]}$. Both venesection and iron chelation therapies do not target the biological mechanisms involved in iron metabolism. HH is characterised by low hepcidin synthesis and clinical trials evaluating the role of therapeutic hepcidin by subcutaneous administration are currently underway. Patients with cirrhosis should undergo six monthly surveillance by ultrasound (with or without alpha-fetoprotein measurement) to detect HCC at an early stage when curative therapy is more likely to be successful. Of interest, liver transplantation remains an option for some patients with HCC within appropriate criteria and this procedure will also normalise hepcidin synthesis and prevent iron overload (provided the donor does not have $\mathrm{HH})^{[117,123]}$.

\section{DISCUSSION}

Early diagnosis and treatment of $\mathrm{HH}$ by preventing the development of cirrhosis may reduce the incidence of HCC in the future. The American Association for the Study of Liver Diseases guidelines recommend regular surveillance for HCC in cirrhotic patients only ${ }^{[9]}$. It has been recommended that screening for HCC be continued throughout life of the HH patients as HCC may develop years after the depletion of iron has been achieved. Whilst controversial, some recommend iron depletion therapy in patients with even minor increases in iron stores, when non-alcoholic fatty liver disease, hepatitis B or C coexist, in an attempt to reduce the risk of progressive fibrosis and subsequent $\mathrm{HCC}^{[72]}$. It is also recommended that family screening for $\mathrm{HH}$ mutations and iron overload in all first-degree relatives of $\mathrm{HH}$ patients be performed. As HFE gene mutation often synergises with other risk factors of HCC, HH patients with known HCC risk factors should be regularly counselled to avoid environmental or toxic injury to the liver.

Besides $\mathrm{HH}$, there are many other causes of iron overloading that result in excessive iron accumulation in the liver and other organs. It has been reported that patients with high total body iron have a higher risk of developing HCC in the absence of $\mathrm{HH}^{[124-126]}$. As iron overload is not a benign condition, it is recommended that HCC surveillance be undertaken in patients with excess body iron, particularly in patients with cirrhosis $^{[127]}$.

Further studies to identify genetic or environmental factors that could act in concert with HFE mutations to increase the risk of developing HCC are warranted. Investigations are underway to determine the role 
of iron-regulatory proteins in abnormal iron uptake in HCC. In-depth understanding of the intricate pathways involved in $\mathrm{HH}$-associated HCC needs attention and future research needs to be focused on the prevention of HCC in these patients.

\section{CONCLUSION}

Despite the controversies in the field regarding the degree of penetrance of HFE mutations in different patient populations and their role in hepatic iron overload, $\mathrm{HH}$ patients with cirrhosis are at a high risk of developing HCC. Further study in this field is needed to better understand the pathogenic process toward HCC and to prevent HCC development in HH patients, considering that there are currently no effective therapies for HCC. Furthermore, an in-depth understanding of the metabolic iron regulatory pathways in HFE-related HCC in $\mathrm{HH}$ patients will allow the discovery of novel druggable targets for effective therapeutic approaches.

\section{DECLARATIONS}

\section{Authors' contributions}

Contributed to conception and design of the study and manuscript writing: Jayachandran A, Shrestha R, Bridle KR, Crawford DHG

Final approval of manuscripts: Jayachandran A, Shrestha R, Bridle KR, Crawford DHG

\section{Availability of data and materials}

Not applicable.

\section{Financial support and sponsorship}

This manuscript publication is funded by Gallipoli Medical Research Foundation.

\section{Conflicts of interest}

All authors declared that there are no conflicts of interest.

\section{Ethical approval and consent to participate}

Not applicable.

\section{Consent for publication}

Not applicable.

\section{Copyright}

(c) The Author(s) 2020.

\section{REFERENCES}

1. Venook AP, Papandreou C, Furuse J, de Guevara LL. The incidence and epidemiology of hepatocellular carcinoma: a global and regional perspective. Oncologist 2010;15:5-13.

2. Siegel RL, Miller KD, Jemal A. Cancer statistics, 2017. CA Cancer J Clin 2017;67:7-30

3. Galun D, Srdic-Rajic T, Bogdanovic A, Loncar Z, Zuvela M. Targeted therapy and personalized medicine in hepatocellular carcinoma: drug resistance, mechanisms, and treatment strategies. J Hepatocell Carcinoma 2017;4:93-103.

4. Llovet JM, Montal R, Sia D, Finn RS. Molecular therapies and precision medicine for hepatocellular carcinoma. Nat Rev Clin Oncol 2018;15:599-616.

5. Ikeda M, Morizane C, Ueno M, Okusaka T, Ishii H, et al. Chemotherapy for hepatocellular carcinoma: current status and future perspectives. Jpn J Clin Oncol 2018;48:103-14.

6. Abou-Alfa GK, Huitzil-Melendez FD, O'Reilly EM, Saltz LB. Current management of advanced hepatocellular carcinoma. Gastrointest Cancer Res 2008;2:64-70.

7. Llovet JM, Burroughs A, Bruix J. Hepatocellular carcinoma. Lancet 2003;362:1907-17.

8. McGlynn KA, Petrick JL, London WT. Global epidemiology of hepatocellular carcinoma: an emphasis on demographic and regional 
variability. Clin Liver Dis 2015;19:223-38.

9. Bacon BR, Adams PC, Kowdley KV, Powell LW, Tavill AS; Diseases AAftSoL. Diagnosis and management of hemochromatosis: 2011 practice guideline by the American Association for the Study of Liver Diseases. Hepatology 2011;54:328-43.

10. Liver EAFTSOT. EASL clinical practice guidelines for HFE hemochromatosis. J Hepatol 2010;53:3-22.

11. Crawford DHG. Hereditary hemochromatosis types 1, 2, and 3. Clin Liver Dis (Hoboken) 2014;3:96-7.

12. Merryweather-Clarke AT, Pointon JJ, Jouanolle AM, Rochette J, Robson KJ. Geography of HFE C282Y and H63D mutations. Genet Test 2000;4:183-98.

13. Olynyk JK, Cullen DJ, Aquilia S, Rossi E, Summerville L, et al. A population-based study of the clinical expression of the hemochromatosis gene. N Engl J Med 1999;341:718-24.

14. Phatak PD, Bonkovsky HL, Kowdley KV. Hereditary hemochromatosis: time for targeted screening. Ann Intern Med 2008;149:270-2.

15. Beutler E. Iron storage disease: facts, fiction and progress. Blood Cells Mol Dis 2007;39:140-7.

16. Gan EK, Powell LW, Olynyk JK. Natural history and management of HFE-hemochromatosis. Semin Liver Dis 2011;31:293-301.

17. Golfeyz S, Lewis S, Weisberg IS. Hemochromatosis: pathophysiology, evaluation, and management of hepatic iron overload with a focus on MRI. Expert Rev Gastroenterol Hepatol 2018;12:767-78.

18. Niederau C, Fischer R, Sonnenberg A, Stremmel W, Trampisch HJ, et al. Survival and causes of death in cirrhotic and in noncirrhotic patients with primary hemochromatosis. N Engl J Med 1985;313:1256-62.

19. Feder JN, Gnirke A, Thomas W, Tsuchihashi Z, Ruddy DA, et al. A novel MHC class I-like gene is mutated in patients with hereditary haemochromatosis. Nat Genet 1996;13:399-408.

20. de Campos WN, Massaro JD, Cançado ELR, Wiezel CEV, Simões AL, et al. Comprehensive analysis of. World J Hepatol 2019;11:186-98.

21. Barton JC, Acton RT. HLA-A and -B alleles and haplotypes in hemochromatosis probands with HFE C282Y homozygosity in central Alabama. BMC Med Genet 2002;3:9.

22. Adams PC, Barton JC. Haemochromatosis. Lancet 2007;370:1855-60.

23. Allen KJ, Gurrin LC, Constantine CC, Osborne NJ, Delatycki MB, et al. Iron-overload-related disease in HFE hereditary hemochromatosis. N Engl J Med 2008;358:221-30.

24. Trifa AP, Popp RA, Militaru MS, Farcaş MF, Crişan TO, et al. HFE gene C282Y, H63D and S65C mutations frequency in the Transylvania region, Romania. J Gastrointestin Liver Dis 2012;21:177-80.

25. Feder JN, Penny DM, Irrinki A, Lee VK, Lebrón JA, et al. The hemochromatosis gene product complexes with the transferrin receptor and lowers its affinity for ligand binding. Proc Natl Acad Sci U S A 1998;95:1472-7.

26. Giannetti AM, Björkman PJ. HFE and transferrin directly compete for transferrin receptor in solution and at the cell surface. J Biol Chem 2004;279:25866-75.

27. Schmidt PJ, Toran PT, Giannetti AM, Bjorkman PJ, Andrews NC. The transferrin receptor modulates Hfe-dependent regulation of hepcidin expression. Cell Metab 2008;7:205-14.

28. Vujić Spasić M, Kiss J, Herrmann T, Galy B, Martinache S, et al. Hfe acts in hepatocytes to prevent hemochromatosis. Cell Metab 2008;7:173-8

29. Zhao N, Zhang AS, Enns CA. Iron regulation by hepcidin. J Clin Invest 2013;123:2337-43.

30. Zhang AS, Enns CA. Molecular mechanisms of normal iron homeostasis. Hematology Am Soc Hematol Educ Program 2009;207-14.

31. Ganz T, Nemeth E. Hepcidin and iron homeostasis. Biochim Biophys Acta 2012;1823:1434-43.

32. Deugnier Y. Iron and liver cancer. Alcohol 2003;30:145-50.

33. Beutler E, Gelbart T, West C, Lee P, Adams M, et al. Mutation analysis in hereditary hemochromatosis. Blood Cells Mol Dis 1996;22:187-94.

34. Mura C, Raguenes O, Férec C. HFE mutations analysis in 711 hemochromatosis probands: evidence for S65C implication in mild form of hemochromatosis. Blood 1999;93:2502-5.

35. Bacon BR, Olynyk JK, Brunt EM, Britton RS, Wolff RK. HFE genotype in patients with hemochromatosis and other liver diseases. Ann Intern Med 1999;130:953-62.

36. Gurrin LC, Bertalli NA, Dalton GW, Osborne NJ, Constantine CC, et al. HFE C282Y/H63D compound heterozygotes are at low risk of hemochromatosis-related morbidity. Hepatology 2009;50:94-101

37. Walsh A, Dixon JL, Ramm GA, Hewett DG, Lincoln DJ, et al. The clinical relevance of compound heterozygosity for the C282Y and H63D substitutions in hemochromatosis. Clin Gastroenterol Hepatol 2006;4:1403-10.

38. Cardoso CS, de Sousa M. HFE, the MHC and hemochromatosis: paradigm for an extended function for MHC class I. Tissue Antigens 2003;61:263-75.

39. Torres FR, Souza-Neiras WC, D'Almeida Couto AA, D'Almeida Couto VS, Cavasini CE, et al. Frequency of the HFE C282Y and H63D polymorphisms in Brazilian malaria patients and blood donors from the Amazon region. Genet Mol Res 2008;7:60-4.

40. Fargion S, Mandelli C, Piperno A, Cesana B, Fracanzani AL, et al. Survival and prognostic factors in 212 Italian patients with genetic hemochromatosis. Hepatology 1992;15:655-9.

41. Kew MD. Pathogenesis of hepatocellular carcinoma in hereditary hemochromatosis: occurrence in noncirrhotic patients. Hepatology 1990;11:1086-7.

42. Elmberg M, Hultcrantz R, Ekbom A, Brandt L, Olsson S, et al. Cancer risk in patients with hereditary hemochromatosis and in their first-degree relatives. Gastroenterology 2003;125:1733-41.

43. Fracanzani AL, Conte D, Fraquelli M, Taioli E, Mattioli M, et al. Increased cancer risk in a cohort of 230 patients with hereditary hemochromatosis in comparison to matched control patients with non-iron-related chronic liver disease. Hepatology 2001;33:647-51.

44. Haddow JE, Palomaki GE, McClain M, Craig W. Hereditary haemochromatosis and hepatocellular carcinoma in males: a strategy for estimating the potential for primary prevention. J Med Screen 2003;10:11-3. 
45. Hsing AW, McLaughlin JK, Olsen JH, Mellemkjar L, Wacholder S, et al. Cancer risk following primary hemochromatosis: a population-based cohort study in Denmark. Int J Cancer 1995;60:160-2.

46. Strohmeyer G, Niederau C, Stremmel W. Survival and causes of death in hemochromatosis. Observations in 163 patients. Ann N Y Acad Sci 1988;526:245-57.

47. Yang Q, McDonnell SM, Khoury MJ, Cono J, Parrish RG. Hemochromatosis-associated mortality in the United States from 1979 to 1992: an analysis of Multiple-Cause Mortality Data. Ann Intern Med 1998;129:946-53.

48. Cauza E, Peck-Radosavljevic M, Ulrich-Pur H, Datz C, Gschwantler M, et al. Mutations of the HFE gene in patients with hepatocellular carcinoma. Am J Gastroenterol 2003;98:442-7.

49. Ezzikouri S, El Feydi AE, El Kihal L, Afifi R, Benazzouz M, et al. Prevalence of common HFE and SERPINA1 mutations in patients with hepatocellular carcinoma in a Moroccan population. Arch Med Res 2008;39:236-41.

50. Fargion S, Stazi MA, Fracanzani AL, Mattioli M, Sampietro M, et al. Mutations in the HFE gene and their interaction with exogenous risk factors in hepatocellular carcinoma. Blood Cells Mol Dis 2001;27:505-11.

51. Hellerbrand C, Pöppl A, Hartmann A, Schölmerich J, Lock G. HFE C282Y heterozygosity in hepatocellular carcinoma: evidence for an increased prevalence. Clin Gastroenterol Hepatol 2003;1:279-84.

52. Lauret E, Rodríguez M, González S, Linares A, López-Vázquez A, et al. HFE gene mutations in alcoholic and virus-related cirrhotic patients with hepatocellular carcinoma. Am J Gastroenterol 2002;97:1016-21.

53. Nahon P, Sutton A, Rufat P, Ziol M, Thabut G, et al. Liver iron, HFE gene mutations, and hepatocellular carcinoma occurrence in patients with cirrhosis. Gastroenterology 2008;134:102-10.

54. Pirisi M, Toniutto P, Uzzau A, Fabris C, Avellini C, et al. Carriage of HFE mutations and outcome of surgical resection for hepatocellular carcinoma in cirrhotic patients. Cancer 2000;89:297-302.

55. Ropero P, Briceño O, López-Alonso G, Agúndez JA, González Fernández FA, et al. The H63D mutation in the HFE gene is related to the risk of hepatocellular carcinoma. Rev Esp Enferm Dig 2007;99:376-81. (in Spanish)

56. Shi WJ, Chen H, Zhou B, Cheng J. Association of mutations of HFE gene and hepatocellular carcinoma following chronic hepatitis B. Zhonghua Gan Zang Bing Za Zhi 2005;13:682-4. (in Chinese)

57. Willis G, Wimperis JZ, Lonsdale R, Fellows IW, Watson MA, et al. Incidence of liver disease in people with HFE mutations. Gut 2000;46:401-4.

58. Willis G, Wimperis JZ, Lonsdale R, Jennings BA. Haemochromatosis gene mutation in hepatocellular cancer. Lancet 1997;350:565-6.

59. Sánchez-Luna SA, Brown KE. Clinical burden of liver disease from hemochromatosis at an academic medical center. Hepatol Commun 2017;1:453-9.

60. Ellervik C, Birgens H, Tybjaerg-Hansen A, Nordestgaard BG. Hemochromatosis genotypes and risk of 31 disease endpoints: metaanalyses including 66,000 cases and 226,000 controls. Hepatology 2007;46:1071-80.

61. Ye Q, Qian BX, Yin WL, Wang FM, Han T. Association between the HFE C282Y, H63D polymorphisms and the risks of nonalcoholic fatty liver disease, liver cirrhosis and hepatocellular carcinoma: an updated systematic review and meta-analysis of 5,758 cases and 14,741 controls. PLoS One 2016;11:e163423.

62. Asberg A, Hveem K, Thorstensen K, Ellekjter E, Kannelønning K, et al. Screening for hemochromatosis: high prevalence and low morbidity in an unselected population of 65,238 persons. Scand J Gastroenterol 2001;36:1108-15.

63. Gharib AF, Karam RA, Pasha HF, Radwan MI, Elsawy WH. Polymorphisms of hemochromatosis, and alpha-1 antitrypsin genes in Egyptian HCV patients with and without hepatocellular carcinoma. Gene 2011;489:98-102.

64. Harrison SA, Bacon BR. Relation of hemochromatosis with hepatocellular carcinoma: epidemiology, natural history, pathophysiology, screening, treatment, and prevention. Med Clin North Am 2005;89:391-409.

65. Tarao K, Nozaki A, Ikeda T, Sato A, Komatsu H, et al. Real impact of liver cirrhosis on the development of hepatocellular carcinoma in various liver diseases-meta-analytic assessment. Cancer Med 2019;8:1054-65.

66. Villanueva A, Newell P, Hoshida Y. Inherited hepatocellular carcinoma. Best Pract Res Clin Gastroenterol 2010;24:725-34.

67. Bradbear RA, Bain C, Siskind V, Schofield FD, Webb S, et al. Cohort study of internal malignancy in genetic hemochromatosis and other chronic nonalcoholic liver diseases. J Natl Cancer Inst 1985;75:81-4.

68. Blanc JF, De Ledinghen V, Bernard PH, de Verneuil H, Winnock M, et al. Increased incidence of HFE C282Y mutations in patients with iron overload and hepatocellular carcinoma developed in non-cirrhotic liver. J Hepatol 2000;32:805-11.

69. Hiatt T, Trotter JF, Kam I. Hepatocellular carcinoma in a noncirrhotic patient with hereditary hemochromatosis. Am J Med Sci 2007;334:228-30.

70. Asare GA, Mossanda KS, Kew MC, Paterson AC, Kahler-Venter CP, et al. Hepatocellular carcinoma caused by iron overload: a possible mechanism of direct hepatocarcinogenicity. Toxicology 2006;219:41-52.

71. Willis G, Bardsley V, Fellows IW, Lonsdale R, Wimperis JZ, et al. Hepatocellular carcinoma and the penetrance of HFE C282Y mutations: a cross sectional study. BMC Gastroenterol 2005;5:17.

72. Fracanzani AL, Fargion S, Stazi MA, Valenti L, Amoroso P, et al. Association between heterozygosity for HFE gene mutations and hepatitis viruses in hepatocellular carcinoma. Blood Cells Mol Dis 2005;35:27-32.

73. Nowak A, Giger RS, Krayenbuehl PA. Higher age at diagnosis of hemochromatosis is the strongest predictor of the occurrence of hepatocellular carcinoma in the Swiss hemochromatosis cohort: a prospective longitudinal observational study. Medicine (Baltimore) 2018;97:e12886.

74. Boige V, Castéra L, de Roux N, Ganne-Carrié N, Ducot B, et al. Lack of association between HFE gene mutations and hepatocellular carcinoma in patients with cirrhosis. Gut 2003;52:1178-81.

75. Jin F, Qu LS, Shen XZ. Association between C282Y and H63D mutations of the HFE gene with hepatocellular carcinoma in European populations: a meta-analysis. J Exp Clin Cancer Res 2010;29:18.

76. Campo S, Restuccia T, Villari D, Raffa G, Cucinotta D, et al. Analysis of haemochromatosis gene mutations in a population from the 
Mediterranean Basin. Liver 2001;21:233-6.

77. Constantine CC, Gurrin LC, McLaren CE, Bahlo M, Anderson GJ, et al. SNP selection for genes of iron metabolism in a study of genetic modifiers of hemochromatosis. BMC Med Genet 2008;9:18.

78. Racchi O, Mangerini R, Rapezzi D, Gaetani GF, Nobile MT, et al. Mutations of the HFE gene and the risk of hepatocellular carcinoma. Blood Cells Mol Dis 1999;25:350-3.

79. Kew MC. Hepatic iron overload and hepatocellular carcinoma. Liver Cancer 2014;3:31-40.

80. Shen Y, Li X, Zhao B, Xue Y, Wang S, et al. Iron metabolism gene expression and prognostic features of hepatocellular carcinoma. J Cell Biochem 2018;119:9178-204.

81. Pantopoulos K. Inherited disorders of iron overload. Front Nutr 2018;5:103.

82. Worthen CA, Enns CA. The role of hepatic transferrin receptor 2 in the regulation of iron homeostasis in the body. Front Pharmacol 2014;5:34.

83. Andrews NC. Disorders of iron metabolism. N Engl J Med 1999;341:1986-95.

84. Nemeth E, Tuttle MS, Powelson J, Vaughn MB, Donovan A, et al. Hepcidin regulates cellular iron efflux by binding to ferroportin and inducing its internalization. Science 2004;306:2090-3.

85. West AP, Bennett MJ, Sellers VM, Andrews NC, Enns CA, et al. Comparison of the interactions of transferrin receptor and transferrin receptor 2 with transferrin and the hereditary hemochromatosis protein HFE. J Biol Chem 2000;275:38135-8.

86. Lesbordes-Brion JC, Viatte L, Bennoun M, Lou DQ, Ramey G, et al. Targeted disruption of the hepcidin 1 gene results in severe hemochromatosis. Blood 2006;108:1402-5.

87. Wu XG, Wang Y, Wu Q, Cheng WH, Liu W, et al. HFE interacts with the BMP type I receptor ALK3 to regulate hepcidin expression. Blood 2014;124:1335-43.

88. Gao J, Chen J, Kramer M, Tsukamoto H, Zhang AS, et al. Interaction of the hereditary hemochromatosis protein HFE with transferrin receptor 2 is required for transferrin-induced hepcidin expression. Cell Metab 2009;9:217-27.

89. Zacharski LR, Ornstein DL, Woloshin S, Schwartz LM. Association of age, sex, and race with body iron stores in adults: analysis of NHANES III data. Am Heart J 2000;140:98-104.

90. Asare GA, Paterson AC, Kew MC, Khan S, Mossanda KS. Iron-free neoplastic nodules and hepatocellular carcinoma without cirrhosis in Wistar rats fed a diet high in iron. J Pathol 2006;208:82-90.

91. Ioannou GN, Kowdley KV. Iron, HFE mutations, and hepatocellular carcinoma: is hepatic iron a carcinogen? Clin Gastroenterol Hepatol 2003;1:246-8.

92. Ramm GA, Crawford DH, Powell LW, Walker NI, Fletcher LM, et al. Hepatic stellate cell activation in genetic haemochromatosis Lobular distribution, effect of increasing hepatic iron and response to phlebotomy. J Hepatol 1997;26:584-92.

93. Yu Y, Kovacevic Z, Richardson DR. Tuning cell cycle regulation with an iron key. Cell Cycle 2007;6:1982-94.

94. Toyokuni S. Role of iron in carcinogenesis: cancer as a ferrotoxic disease. Cancer Sci 2009;100:9-16.

95. Fargion S, Valenti L, Fracanzani AL. Role of iron in hepatocellular carcinoma. Clin Liver Dis (Hoboken) 2014;3:108-10.

96. Moukhadder HM, Halawi R, Cappellini MD, Taher AT. Hepatocellular carcinoma as an emerging morbidity in the thalassemia syndromes: a comprehensive review. Cancer 2017;123:751-8.

97. Marshall A, Lukk M, Kutter C, Davies S, Alexander G, Odom DT. Global gene expression profiling reveals SPINK1 as a potential hepatocellular carcinoma marker. PLoS One 2013;8:e59459.

98. Miyanishi K, Tanaka S, Sakamoto H, Kato J. The role of iron in hepatic inflammation and hepatocellular carcinoma. Free Radic Biol Med 2019;133:200-5.

99. Muto Y, Moroishi T, Ichihara K, Nishiyama M, Shimizu H, et al. Disruption of FBXL5-mediated cellular iron homeostasis promotes liver carcinogenesis. J Exp Med 2019;216:950-65.

100. Hussain SP, Hollstein MH, Harris CC. p53 tumor suppressor gene: at the crossroads of molecular carcinogenesis, molecular epidemiology, and human risk assessment. Ann N Y Acad Sci 2000;919:79-85.

101. Ichiba M, Maeta Y, Mukoyama T, Saeki T, Yasui S, et al. Expression of 8-hydroxy-2'-deoxyguanosine in chronic liver disease and hepatocellular carcinoma. Liver Int 2003;23:338-45.

102. Valerio LG, Petersen DR. Characterization of hepatic iron overload following dietary administration of dicyclopentadienyl iron (Ferrocene) to mice: cellular, biochemical, and molecular aspects. Exp Mol Pathol 2000;68:1-12.

103. Kowdley KV. Iron, hemochromatosis, and hepatocellular carcinoma. Gastroenterology 2004;127:S79-86.

104. Olynyk JK, St Pierre TG, Britton RS, Brunt EM, Bacon BR. Duration of hepatic iron exposure increases the risk of significant fibrosis in hereditary hemochromatosis: a new role for magnetic resonance imaging. Am J Gastroenterol 2005;100:837-41.

105. Cabantchik ZI, Breuer W, Zanninelli G, Cianciulli P. LPI-labile plasma iron in iron overload. Best Pract Res Clin Haematol 2005; 18:277-87.

106. Asare GA, Bronz M, Naidoo V, Kew MC. Synergistic interaction between excess hepatic iron and alcohol ingestion in hepatic mutagenesis. Toxicology 2008;254:11-8.

107. Nahon P, Sutton A, Pessayre D, Rufat P, Charnaux N, et al. Do genetic variations in antioxidant enzymes influence the course of hereditary hemochromatosis? Antioxid Redox Signal 2011;15:31-8.

108. Houglum K, Bedossa P, Chojkier M. TGF-beta and collagen-alpha 1 (I) gene expression are increased in hepatic acinar zone 1 of rats with iron overload. Am J Physiol 1994;267:G908-13.

109. Wallace DF, Subramaniam VN. Co-factors in liver disease: the role of HFE-related hereditary hemochromatosis and iron. Biochim Biophys Acta 2009;1790:663-70.

110. Hann HW, Stahlhut MW, Hann CL. Effect of iron and desferoxamine on cell growth and in vitro ferritin synthesis in human hepatoma cell lines. Hepatology 1990;11:566-9.

111. Shen Y, Li X, Su Y, Badshah SA, Zhang B, et al. Downregulation contributes to aggressive hepatocellular carcinoma via mechanism 
mediated by cyclin4-dependent kinase-1/STAT3 pathway. Diagnostics (Basel) 2019;9.

112. Djeha A, Brock JH. Effect of transferrin, lactoferrin and chelated iron on human T-lymphocytes. Br J Haematol 1992;80:235-41.

113. Green R, Esparza I, Schreiber R. Iron inhibits the nonspecific tumoricidal activity of macrophages. A possible contributory mechanism for neoplasia in hemochromatosis. Ann N Y Acad Sci 1988;526:301-9.

114. Cozma A, Fodor A, Vulturar R, Sitar-Tăut AV, Orăşan OH, et al. DNA methylation and micro-RNAs: the most recent and relevant biomarkers in the early diagnosis of hepatocellular carcinoma. Medicina (Kaunas) 2019;55.

115. Lehmann U, Wingen LU, Brakensiek K, Wedemeyer H, Becker T, et al. Epigenetic defects of hepatocellular carcinoma are already found in non-neoplastic liver cells from patients with hereditary haemochromatosis. Hum Mol Genet 2007;16:1335-42.

116. Adams P, Altes A, Brissot P, Butzeck B, Cabantchik I, et al. Therapeutic recommendations in HFE hemochromatosis for p.Cys282Tyr (C282Y/C282Y) homozygous genotype. Hepatol Int 2018;12:83-6.

117. Loréal O, Cavey T, Robin F, Kenawi M, Guggenbuhl P, et al. Iron as a therapeutic target in HFE-related hemochromatosis: usual and novel aspects. Pharmaceuticals (Basel) 2018;11.

118. Phatak P, Brissot P, Wurster M, Adams PC, Bonkovsky HL, et al. A phase 1/2, dose-escalation trial of deferasirox for the treatment of iron overload in HFE-related hereditary hemochromatosis. Hepatology 2010;52:1671-779.

119. Tauchenová L, Kř́̌žová B, Kubánek M, Fraňková S, Melenovský V, et al. Successful treatment of iron-overload cardiomyopathy in hereditary hemochromatosis with deferoxamine and deferiprone. Can J Cardiol 2016;32:1574.e1-e3.

120. Whitnall M, Howard J, Ponka P, Richardson DR. A class of iron chelators with a wide spectrum of potent antitumor activity that overcomes resistance to chemotherapeutics. Proc Natl Acad Sci U S A 2006;103:14901-6.

121. Richardson DR, Tran EH, Ponka P. The potential of iron chelators of the pyridoxal isonicotinoyl hydrazone class as effective antiproliferative agents. Blood 1995;86:4295-306.

122. Wadler S, Makower D, Clairmont C, Lambert P, Fehn K, et al. Phase I and pharmacokinetic study of the ribonucleotide reductase inhibitor, 3-aminopyridine-2-carboxaldehyde thiosemicarbazone, administered by 96 -hour intravenous continuous infusion. J Clin Oncol 2004;22:1553-63.

123. Fung E, Sugianto P, Hsu J, Damoiseaux R, Ganz T, et al. High-throughput screening of small molecules identifies hepcidin antagonists. Mol Pharmacol 2013;83:681-90.

124. MacPhail AP, Mandishona EM, Bloom PD, Paterson AC, Rouault TA, et al. Measurements of iron status and survival in African iron overload. S Afr Med J 1999;89:966-72.

125. Mandishona E, MacPhail AP, Gordeuk VR, Kedda MA, Paterson AC, et al. Dietary iron overload as a risk factor for hepatocellular carcinoma in Black Africans. Hepatology 1998;27:1563-6.

126. Turlin B, Juguet F, Moirand R, Le Quilleuc D, Loréal O, et al. Increased liver iron stores in patients with hepatocellular carcinoma developed on a noncirrhotic liver. Hepatology 1995;22:446-50.

127. Blonski W, Kotlyar DS, Forde KA. Non-viral causes of hepatocellular carcinoma. World J Gastroenterol 2010;16:3603-15. 